\title{
TWO HUNDRED YEARS OF COLOMBIAN ECONOMIC GROWTH: THE ROLE OF TFP*
}

\section{Alvaro J. Riascos*}

Using modern growth theory, we estimate Colombian total-factor productivity relative to the United Kingdom's for the last 200 years in order to match observed income differences. Our results show Colombia's remarkably inefficient use of technology relative to a country that is a leader in this regard and provide quantitative estimates of the proximate causes of relative income differences between the two economies.

JEL classification: N1, N16, O47

Keywords: Long-run growth, total factor productivity, industrialization, Colombia, relative income differences

\section{INTRODUCTION}

Over the last 200 years, Colombian living standards (per capita real gross domestic product, or RGDP) have not improved relative to leading developed economies. There has been growth but no catch-up, as is evident from Figure 1, which shows Colombian RGDP relative to RGDP of the U.K. since the beginning of the 19 th century. ${ }^{1}$ This characteristic is shared by many developing countries and is a stylized fact that has motivated a great deal of research on economic growth. In this paper, we measure and highlight the proximate causes of this relative stagnation, as a prerequisite for a disciplined exploration of the fundamental causes of this phenomenon. The paper focuses on the role of technology and Colombian use of this technology relative to a country that is a leader in this regard.

\footnotetext{
* This paper was prepared for the conference on "Two Centuries of Economic Growth: Latin America at its Bicentennial Celebration" held in Santiago, Chile in December 2010 and sponsored by the Pontificia Universidad Católica de Chile. The paper is part of the special inaugural issue of the Latin American Journal of Economics. We would like to thank organizers Felipe Zurita and Raimundo Soto for the invitation and hospitality and the other conference participants for their helpful comments and suggestions. I am particularly grateful to Alejandro Gaviria and Miguel Urrutia, who were initially coauthors but were unable to spend as much time on the project as needed. Many thanks to them for all of their collaboration, comments and suggestions. I would also like to thank the participants of the CEDE economics seminar at the Universidad de los Andes, the economics seminar at the Universidad del Rosario, the Department of Economics of the Universidad de los Andes for financial support, María del Pilar López for providing us with a unique 19th century data set, Salomon Kalmanovitz for making his 19th century estimates of RGDP available and David Monroy for his excellent research assistance. All remaining errors are my own.

** Department of Economics, Universidad de los Andes. E-mail address: ariascos@uniandes.edu.co 1. See the Appendix for a description of the data used.
} 
Figure 1. Relative per capita RGDP between Colombia and United Kingdom

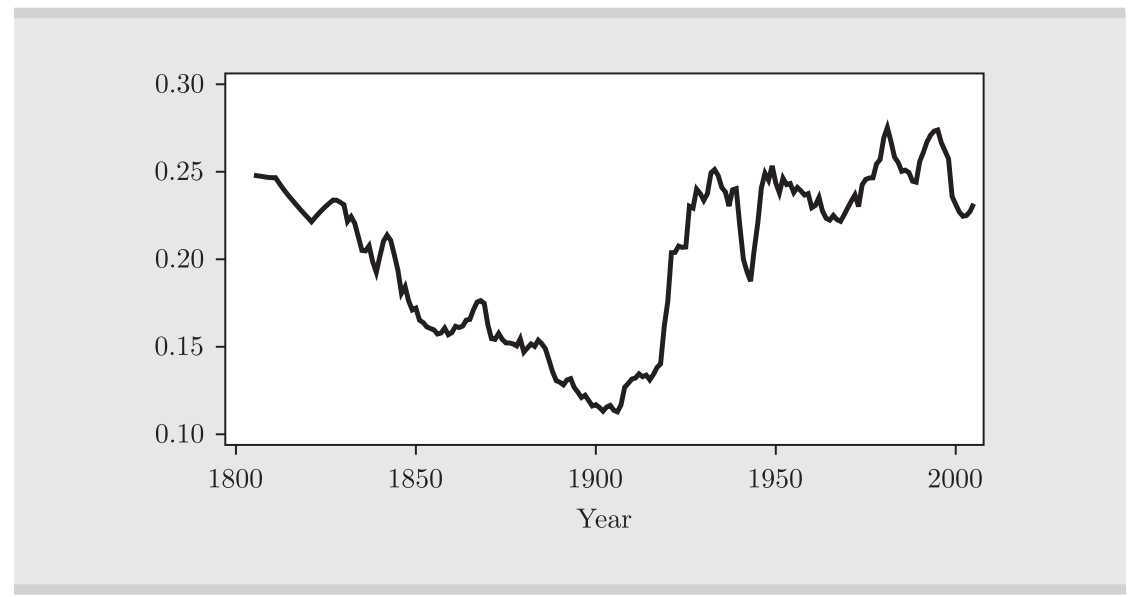

In order to do so, we first document the development pattern of Colombia relative to countries that are now industrialized economies. Using modern growth theory, we measure Colombia's total-factor productivity (TFP) relative to an artificial benchmark economy and the growth experience of the U.K. The model is an extension of Hansen and Prescott (2002) and has several virtues. First, by endogenizing some key macroeconomic variables such as capital, we are able to estimate relative TFP without using capital (which is difficult to estimate for the 19th century). Second, our results are general equilibrium outcomes. In this model, TFP today affects implied TFP tomorrow through the process of capital accumulation, consumption and fertility rates. Third, it tells a unified albeit oversimplified story of the transition from constant living standards (Malthusian economy) and the process of industrialization to modern, sustained growth (Solow's model of economic growth).

There is a growing line of literature focusing on long-run patterns and models of growth starting from the eve of industrialization through modern, sustained economic growth of developed economies (Lucas 2002). Likewise, there is a vast body of literature focusing on the determinants of growth -- proximate and fundamental causes -some of which is largely focused on explaining relative income levels among countries. Our paper is part of this body of literature and makes use of a growth model to study the determinants of Colombian 
economic growth over the last 200 years. There is obviously a growing and important literature on Colombia's long-run economic history (Urrutia and Robinson, 2007; Meisel and Ramírez, 2010), most of which consists of descriptive, qualitative or conceptual efforts to understand Colombia's long-run development pattern. ${ }^{2}$ However, this is probably the first paper that, arguably from a very simplified perspective, studies Colombian long-run growth within a structural and quantitative model of the Colombian economy. Despite its limitations, we hope the results of this paper bring to the forefront of literature on Colombian economic history some important quantitative questions to be solved by future research.

Our main result is an estimation of Colombia's total-factor productivity over the last 200 years relative to an industrialized leader, the United Kingdom. We show that in order to explain Colombia's relative income stagnation, TFP differences must be substantial. To explain how industrialization in Colombia (which occurred around 1910) was delayed almost 75 years after industrialization in England (at the beginning of the 19th century) requires a TFP difference between 0.57 and 0.79 ; and explaining the income differences in the 20th century requires TFP differences to be around 0.51 for the first half of the century and 0.86 for the second half. In Section 5 we provide an interpretation of these results.

The paper is organized as follows. Following this introduction there are four more sections. The second section highlights key stylized facts about the long-run economic growth of the United Kingdom, the United States and Colombia. We take these salient features as restrictions for our modeling framework. The third section briefly describes the model, in particular the main difference with the Hansen and Prescott (2002) model. The fourth section presents the results and the fifth section provides a tentative explanation and concluding remarks. Finally, the Appendix provides references to all of the data used.

\section{Patterns of LONG-RUN GROWTH}

According to economic historians, before the 19th century per capita RGDP was almost constant in all countries (i.e., income and population grew at the same rate), population growth was low, real salaries were 
constant and correlated with population shocks, land was an important factor of production and technological progress was slow (Mokyr, 1990, and Lucas, 2002). We call this economic state a Malthusian economy. Then, on the eve of the 19th century, Europe underwent a dramatic change in all aspects of society. The industrial revolution that started in England in the late 18th century may be the most important event affecting economic and social life over the last 200 years. Before the industrial revolution, the main economic indicators were as described in the previous paragraph. After the industrial revolution, some countries began to grow at unprecedented rates. As a consequence and/or simultaneously, population growth rates and real wages increased substantially. Since then, similar growth patterns characterize today's industrialized economies.

Although this development pattern first took place in England at the end of the 18th century, it has spread slowly to many other developing countries, and according to some authors will be experienced, sooner or later, by almost every country (Lucas, 2002). According to this literature, the stylized fact of long-run development is the transition from the Malthusian economy to a modern industrialized economy or a Solow economy. From the point of view of this study, the most salient feature of the latter is the sustained and constant growth of living standards. More precisely, RGDP and real wages grow at a constant rate that is equal to the rate of growth of technological progress. These and other regularities documented as Kaldor stylized facts have a standard rationalization in the Solow growth model. ${ }^{3}$ Therefore, and following Hansen and Prescott (2002), we take this pattern of a Malthusian economy followed by a transition to a Solow economy as our basic long-run growth pattern.

Given that this transition has taken place in different countries at various times in history, it comes as no surprise that the uneven pace of the industrial revolution has given rise to an enormous inequality in living standards as measured in terms of per capita RGDP. We follow Parente and Prescott (2000) and many others in explaining these income differences as the consequence of inefficient use of technology relative to a technological frontier.

Finally, another important feature during this transition, as documented by Lucas (2002) is the so-called demographic transition, which consists 
of a pattern of low population growth rates followed by very rapid transitions to higher growth rates and, finally, a return to lower rates.

Figures 2 to 6 illustrate some of these long-run patterns of economic growth. Figure 2 shows U.S. and U.K. per capita RGDP, population and real wages over the last 200 years. Both per capita RGDP and real wages tell similar stories. During the 19th century, U.S. per capita RGDP grew very little (Malthusian economy). Then, at the beginning of the 20th century, there was a structural change in per capita RGDP and real wage growth rates. This pattern coincides with U.S. economic history and the basic facts mentioned previously. During the Malthusian period, per capita RGDP and real wages were almost constant, and then after a transition period the economy evolved into a Solow industrialized economy where per capita RGDP and wages grow at the same rate as the rate of growth of TFP. In terms of those same variables, the U.K.'s economic history is similar but leads the U.S. economy by between 80 and 100 years. That is, the U.K. is a Malthusian economy at the beginning of the 19 th century, then makes a major transition towards a modern industrialized economy that is well described as a Solow economy. In terms of the demographic transition, the story is very different. On the one hand, the U.K. follows a pattern that is largely consistent with the stylized fact mentioned previously: a period of low population growth followed by a substantial increase in population growth and finally a relative low population growth rate. Moreover, this pattern is consistent with the view of Lucas (2002) of a radical change in fertility rates on the eve of the Industrial Revolution. On the other hand, the U.S population growth rates in the 19 th century reflect greater immigration rather that a change in fertility rates. U.S economic history locates its demographic transition in the middle of the 20th century, well after the U.S. started is industrialization process and for very different reasons.

Figure 3 shows an interesting historical fact. While the U.K. historically took the lead in terms of technological change and per capita RGDP growth, the U.S. began to catch up in the second half of the 19th century, and by the end of the first quarter of the 20th century it had already taken the lead in terms of income per capita. This suggests that our estimation of relative TFP differences between Colombia and the U.K. over the last 200 years is a lower bound to relative TFP differences between Colombia and the U.S. for the same period and most notably in the 20th century. 


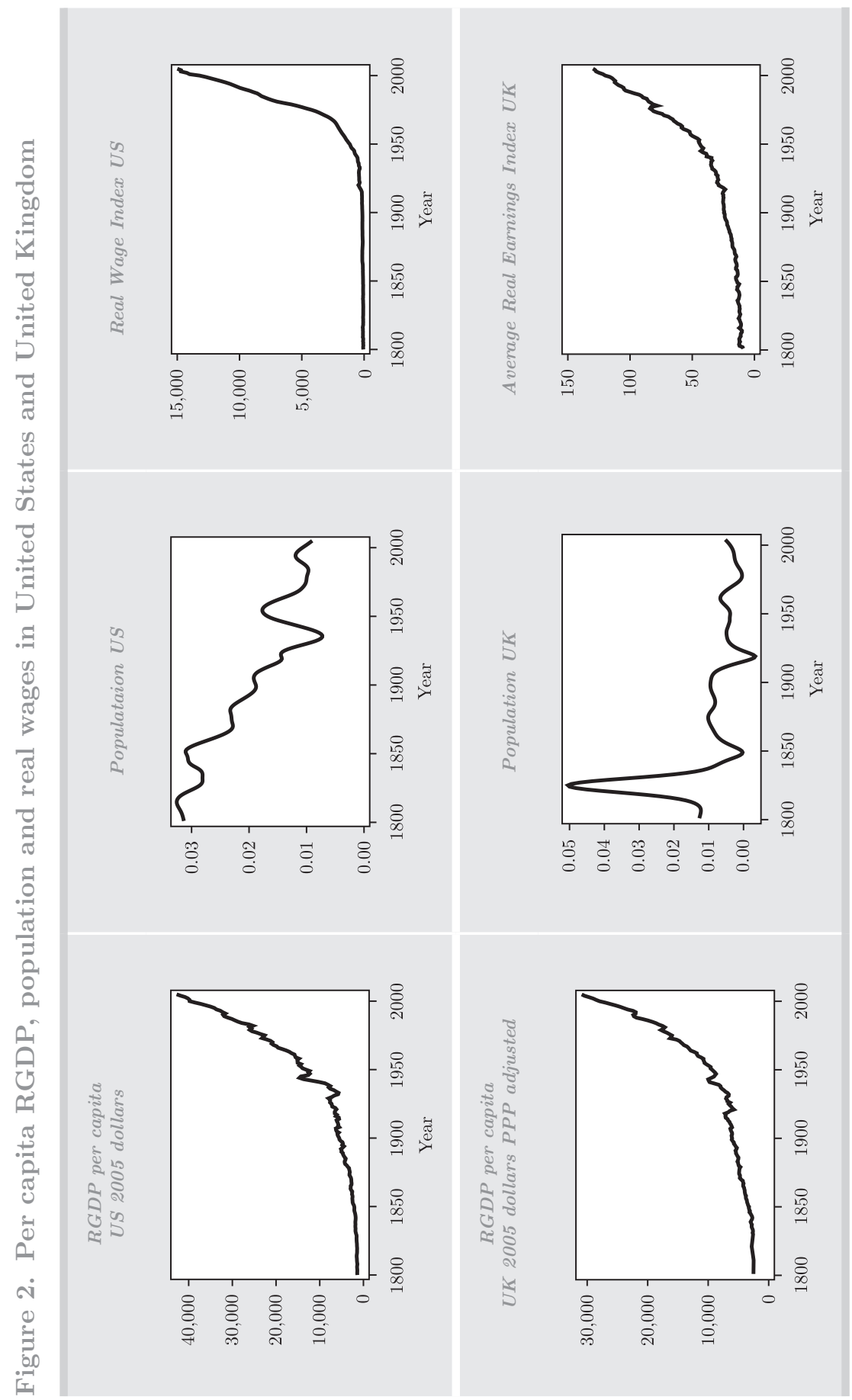


Figure 3. Relative per capita RGDP

between United States and United Kingdom

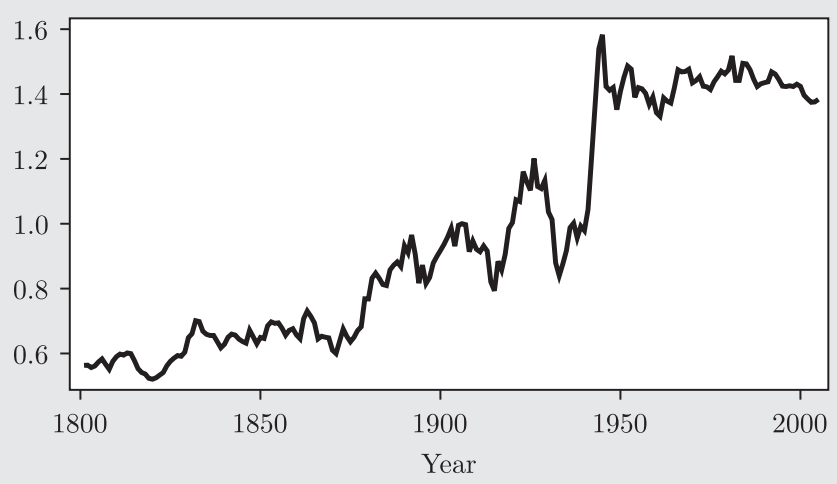

Figure 4. Colombia's per capita RGDP (2005 U.S dollars)

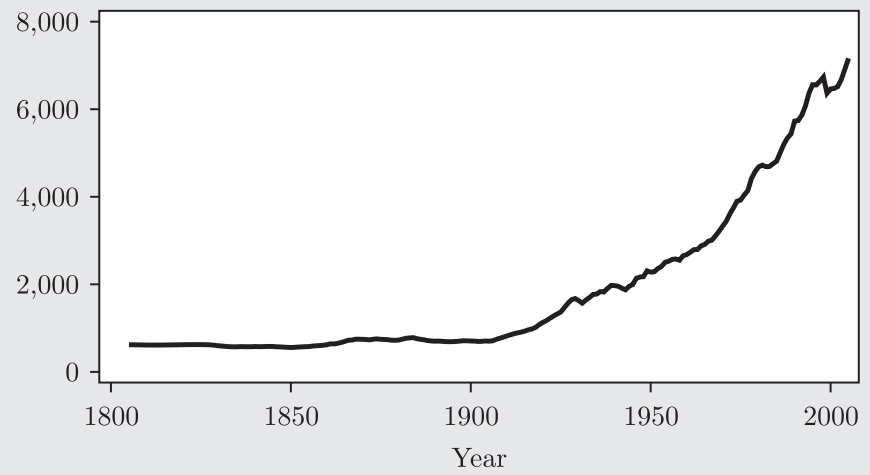

Studying Colombia's long-run economic development in terms of the same dimensions, we find several interesting features that are consistent with our model. Figure 4 shows Colombian per capita RGDP over the last 200 years. The transition from a Malthusian economy (constant living standards) to a Solow economy is obvious. In terms of per capita RGDP, sustained growth began early in the 20th century, which is consistent with historical accounts of Colombian industrialization. In terms of real wages, shown in Figure 6, the message is similar though 
Figure 5. Smoothed Colombian population growth rate

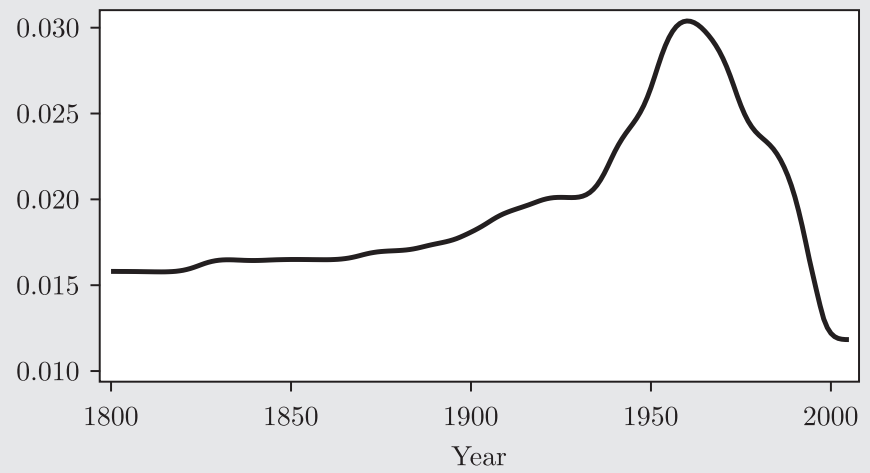

Figure 6. Smoothed Colombian real wages index

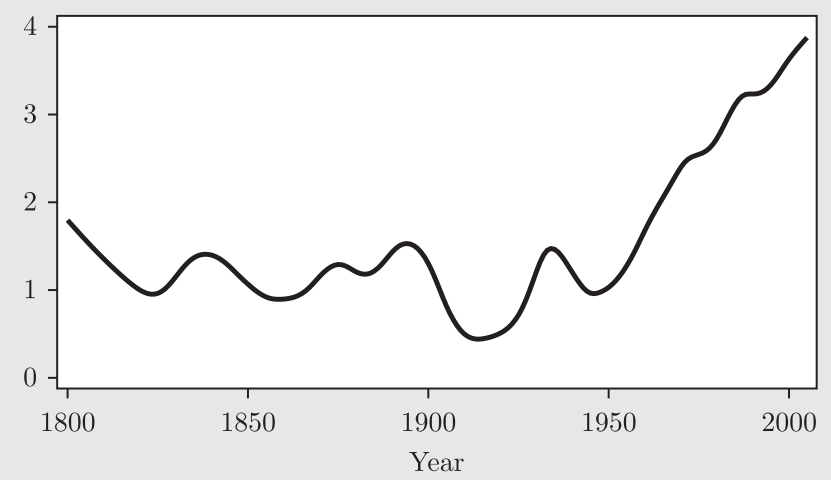

not as clear at least regarding real wages at the beginning of the 20th century. Nevertheless, there may be several good reasons why real wages behave slightly differently than what we would expect from the Solow growth model. First, real wages data are constructed by averaging (see the Appendix) over many sources of nominal data that are not very reliable. Second, and most importantly, at the beginning of the 20th century Colombia (1899-1902) experienced a devastating civil war that 
laid the ground for the separation of what is today the country of Panamá. Known as the Guerra de los Mil Días (the 1,000 Day War), this civil war significantly disrupted Colombia's economic and social life. In any case, it is apparent from Figure 6 that if one smoothes out the data from the first 10 or 20 years of the 20 th century, real wages grow at a constant rate very much in line with the predictions of the Solow growth model.

Finally, and particularly interesting from our modeling framework, the demographic transition is a salient feature of Colombian demographics in the 20th century. First, during the 19th century, growth rates were low. Following the industrialization of the Colombian economy at the beginning of the 20th century, the population growth rate increased and only began to fall back to low levels after the 1960s. Second, as opposed to the previously mentioned stylized facts of long-run growth according to which the demographic transition was almost simultaneous with increases in living standards, in Colombia such an increase did not take place until several decades after industrialization. Third, the demographic transition in our model matches quite well the Colombian experience rather than the previously mentioned stylized facts about industrializations and demographic transitions as documented in Lucas (2002).

\section{THE MODEL}

Hansen and Prescott (2002) define a Malthusian economy as one with constant per capita RGDP (i.e., income and population grow at the same rate), a low population growth rate, almost constant real salaries that are negatively correlated with population shocks and an intensive use of a fixed factor of production (land). On the other hand, by a Solow economy we mean an economy characterized by sustained per capita real GDP growth that matches the rate of growth of technological innovation, exogenous technological progress and real wages that grow at the rate of per capita RGDP. Our working hypothesis is that per capita income differences may be explained by relative TFP (efficient use of technology relative to the technological frontier).

Our model is the same as Hansen and Prescott except for the introduction of a total factor productivity parameter that we calibrate from observable time series of per capita RGDP. We refer the reader to Hansen and Prescott for most of the details while focusing here only 
on the way we have modified and applied their model. The model is a two-period OLG model that will run for six periods. Every period has duration of 35 years and fertility depends on the current to Malthus consumption. The functional form matches Lucas (2002) and Hansen and Prescott (2002) and is given by:

$$
N_{t+1}=N_{t} g\left(c_{t} / c_{M}\right)
$$

where $N_{t}$ is population in period t, $c_{t}$ is current consumption (relative to output) and $c_{M}$ is steady-state consumption in a Malthusian economy (relative to output). Every period there are two available technologies, a Malthus technology and a Solow technology. Whether one or both are used depends on profits and capital-labor allocation between sectors. The only difference between our model and that of Hansen and Prescott is reflected in the following specifications of technologies in both sectors. ${ }^{4}$ The Malthusian sector production technology is:

$$
Y_{M, t}=A_{M, t} \gamma_{M}^{t} K_{M, t}^{\phi} N_{M, t}^{\mu} L_{M, t}^{1-\phi-\mu}
$$

where $Y_{M, t}$ is output using Malthusian technology, $A_{M, t}$ is TFP in the Malthusian sector, $K_{M, t}$ and $N_{M, t}$ are capital and labor respectively, and $L_{M, t}$ is land. In the Solow sector, we assume that production technology takes the form:

$$
Y_{S, t}=A_{S, t} \gamma_{S}^{t} K_{S, t}^{\theta} N_{S, t}^{1-\theta}
$$

where $Y_{S, t}$ is output using Solow technology, $A_{S, t}$ is TFP in the Solow sector and $K_{S, t}$ and $N_{S, t}$ are capital and labor, respectively.

We assume that these technologies are common to all countries except for the level of TFP, $A_{M, t}$ and $A_{S, t}$. Now, regarding the calibration of the model, we use Hansen and Prescott (2002) calibration for all parameters except for TFP. ${ }^{5}$ That is, the calibration is consistent and determined by a few long-run growth facts of the U.K. economy: population growth in the Malthus era, growth rate of TFP in the postwar United States (this is TFP growth rate of the technological leader), capital and labor shares in the Malthus period and the capital

4. Notice that although Hansen and Prescott set up the model in this more general form, they don't solve the model but normalize total factor productivity to one.

5. See Hansen and Prescott (2002), Table 3. 
Figure 7. Facts to be explained: Relative income differences and timing of industrialization in Colombia and United Kingdom

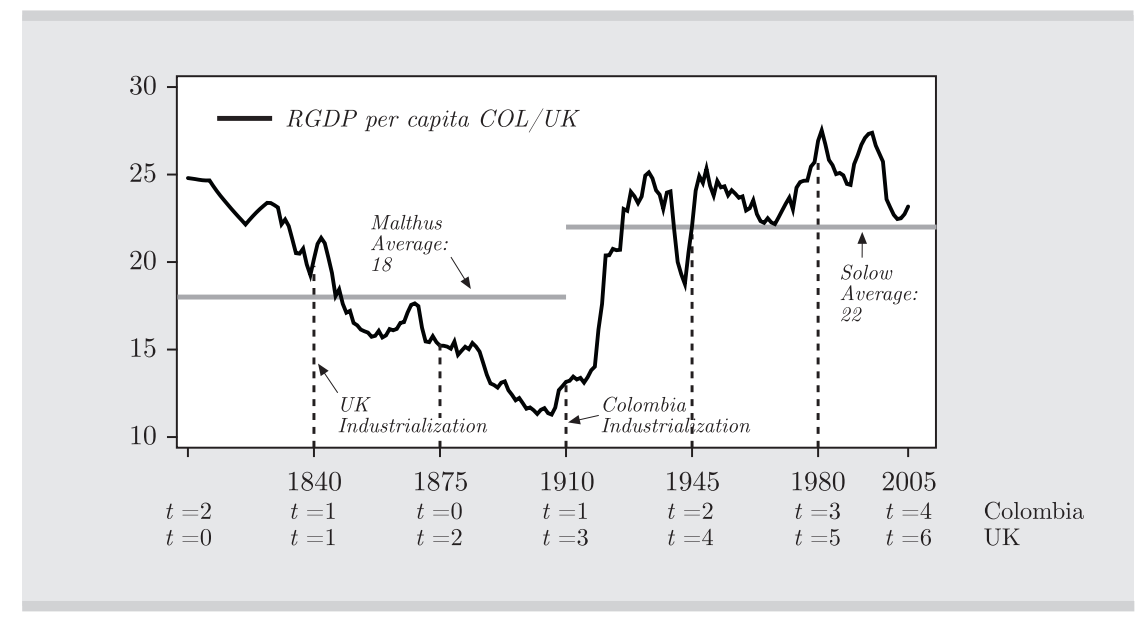

share in Solow technology based on factor shares in the postwar United States. Now, our goal is to model per capita RGDP between Colombia and the U.K. imposing certain restrictions, all of which are illustrated in Figure 7. First, in examining Colombian-U.K. relative RGDP over the last 200 years, there are 5 vertical lines in the figure. Each represents a period in our model (35 years). Then, on the horizontal axis there are two time lines. In each one of them the period between $t=0$ and $t=1$ represents the first time that the Solow technology begins to be used in each country. This marks the very beginning of industrialization. Only by the end of the period, after 35 years, does the Solow technology play a dominant role and it is at this time we can say that industrialization has taken place. For the U.K., that corresponds to somewhere around 1840 and for Colombia it is around 1910 , based on the rate of growth of RGDP in each country (figures 2 and 4) as explained before. These two periods are highlighted by vertical lines representing U.K. and Colombian industrialization. So far, we have placed two broad restrictions on our model. On the one hand, it must reproduce relative per capita RGDP between the two countries for the whole period and second, it must be consistent with the timing of industrialization in both countries (around 1840 for the U.K. and around 1910 for Colombia). For simplicity's sake, we have made our model consistent with the average relative income differences 
between the two countries during the Colombian Malthusian period and thereafter we match relative income differences in the next two periods (1910 - 1945 and 1945 - 1980). That is, we match the Malthus average income difference between the two countries of 0.18 , illustrated by a horizontal line in Figure 7. These restrictions allow us to estimate relative TFP in each sector, Malthus and Solow, for the periods of study as explained below.

\section{Results}

We first notice that the benchmark calibration where total factor productivity is normalized to one as in Hansen and Prescott (2002) underestimates output per capita compared to the U.K. experience over the last 200 years. Therefore, the relative TFP differences estimated in our model will underestimate the real relative TFP differences. ${ }^{6}$ We first calibrated relative TFP between U.K. and Colombia in the Malthusian sector in order to match observed income differences between the two economies when both are in their Malthusian steady state.

Next, notice that the dynamics of income per capita and real wages in Colombia underwent a significant change around 1910. Therefore, we calibrate relative TFP in the Solow sector in such a way that it is only in 1910 that the Solow technology starts to dominate. Basically, this event relies on proposition 2 in Hansen and Prescott (2002). Our interpretation suggests that these are the technological differences that would explain why Colombia's industrialization occurred 70 years after the U.K.'s industrialization. Once Solow technology starts operating in the Colombian economy, we estimate TFP differences by matching relative per capita RGDP for two more periods in the model. That is, average relative per capita RGDP between Colombia and the U.K. for the 1910-1945 period and for the 1945-1980 period.

We examine UK industrialization as a phenomenon starting in 1840 (which was the first time the Solow technology became dominant). This is because when one looks at the data, income per capita in the U.K. was rather constant until 1842. In fact, in 1801, U.K. income per capita was about 2,515 PPP-adjusted 2005 U.S. dollars while in 1842,

6. Formally we set the productivity parameters of the industrial leader to 1 (UK in our exercise). We then estimate $A_{M, t}$ and $A_{S, t}$ for the follower (Colombia) in order to match relative income differences between the two countries. Since normalizing the leader's total factor productivity parameters to 1 underestimates the true income level of the leader during the last two hundred years, our estimate of relative TFP will also be underestimated. 
it was about 1,695. From then on, the U.K. embarked on a period of sustained growth. In order to match the relative income per capita in the U.K. prior to industrialization (the Malthusian period roughly before 1840) with the Colombian pre-industrialization period which was roughly before 1910 (the Colombian Malthusian period), we need relative efficiency of both sectors to be 0.38 . That is, our first result shows that Colombia's productivity during the Malthusian period was at most 0.38 of U.K. productivity during its Malthusian period. Since in both economies during the Malthusian period only the Malthusian technology is being used, this productivity difference corresponds to differences in the Malthusian production technology.

To delay Colombian industrialization, the profitable operation of a Solow technology, we require that productivity differences between the U.K. and Colombia be less than 0.79 and higher than 0.57. The first number is an upper bound for relative productivity differences in order to delay Colombian industrialization by 70 years. Had productivity differences been lower, Colombian industrialization would have taken place before 1910. The second number bounds relative productivity inefficiency between Solow sectors in both countries. Had productivity inefficiency been greater, industrialization would have taken place after 1910. The interval reflects the time discreteness of our model. When industrialization begins in Colombia we set the relative inefficiency of the Malthusian sector in both countries at 0.38. Although this is not necessarily the case for the 1910 - 1980 period it allows us to focus on technological differences in the Solow sector. The results should not be very sensitive to this assumption since Solow technologies very quickly make up most of the share of total output. We then carry on the exercise of matching relative income per capita in both countries for the next two periods after industrialization begins. For the 1910-1945 period we estimate Colombian productivity in the Solow sector to be 0.51 of U.K. productivity in the Solow sector. For the 1945-1980 period the same exercise gives 0.86 . Our main results are summarized in Table 1.

\section{Table 1. Relative TFP between Colombia and UK}

\begin{tabular}{lccc}
\hline Sector & Before 1910 & Between 1910 - 1945 & Between 1945 - 1980 \\
\hline Malthus & $0.38^{\mathrm{a}}$ & 0.38 & 0.38 \\
Solow & {$[0.57,0.79]$} & 0.51 & 0.86 \\
\hline & & \\
\hline
\end{tabular}




\section{INTERPRETATION AND CONCLUDING REMARKS}

Colombia's economic growth has been the subject of numerous studies. However, unlike most specialized literature on the subject, this paper uses a well-defined economic model as a tool to measure the proximate causes of Colombia's income differences relative to the U.K. In particular, the main focus is on measuring technological differences that, given the results presented, provide some valuable lessons and more prominently, guidance for future research. In the literature on Colombia's economic history, there are two dominant approaches. On the one hand, there are very focused studies that describe and measure relevant growth determinants such as trade, transportation costs, political institutions, etc. (an example is Meisel and Ramírez, 2010), and on the other hand, there are more general and descriptive studies such as those in well-known books on Colombian economic history. In all of this literature, the authors provide compelling arguments why various factors are key determinants of economic growth. For example, Ocampo (2010) in Meisel and Ramírez (2010) argues that the weak capacity of the Colombian economy to develop core export products may be essentially responsible for Colombia's slow economic growth in the 19th century. ${ }^{7}$ Although compelling, the study provides no estimate of the extent to which it is responsible and how exactly this could explain Colombia's poor growth. Consider also the comments in Kalmanovitz (2010) who argues that if Colombia performed well in the second half of the 19th century, this was due to favorable terms of trade. ${ }^{8}$ In his conclusions to Chapter 2, Kalmanovitz argues that liberal reforms such as openness to trade, simplification of the tax structure, fiscal federalism and private banking had positive growth effects. Again, the arguments are compelling, but it is hard to know their relative importance, which would be very valuable in the design of economic policy. Now, this paper highlights the role of TFP and its inefficient use as a key determinant of Colombia's economic performance in relation to an industrialized leader. In light of these results, I argue that some of these explanations may be of secondary importance since it is difficult to link some of the arguments mentioned previously and the efficient use of technology. It is in this sense that our model disciplines and guides the discussion by making a case for arguments that help to explain technological inefficiencies. For

7. Chapter 4, pp. 200 of Meisel and Ramírez (2010).

8. Chapter 2, pp. 91 of Kalmanovitz (2010). 
example, the important role played by the tobacco export industry in the second half of the 19th century after many years of state monopoly is widely recognized by economic historians. It was only in 1850 that this monopoly was abolished in favor of greater competition and private entrepreneurship. This historical fact hints at the role of competition policy in economic efficiency. A more obvious guess is related to traditional views on what affects technological progress, such as human capital, appropriate institutions and exogenous conditions such as geography and particularly topography.

According to Maloney (2002), citing Mariscal and Sokoloff (2000), the literacy rate in the United States was around $80 \%$ and $90 \%$ in 1870 and 1970, respectively, while for most Latin American countries the same statistics were below $20 \%$ and $75 \%$. As pointed out by Ramírez and Salazar (2010), by the middle of the 19th century, Colombia's educational level, measured in terms of years of primary schooling, was one of the worst in the world. Primary schooling attainment in the United States was around 20\%, in Holland and the United Kingdom it was around $10 \%$ while in Colombia it was below $2 \%$. Even more dramatic are the differences in technical education measured in terms of engineers per 100,000 workers. Maloney (2002), citing several studies, reports that in the United States in 1920 there were 128 engineers per 100,000 workers, while Sweden had 84 in 1887 and Colombia had just eight in that same year.

Regarding the appropriateness of institutions, there is vast literature that highlights the importance of private property, political institutions, and other institutions for economic growth. Although this paper is not the place to link this literature to what we believe may be important determinants of technological progress, we would like to suggest that political instability and continuous civil conflict are likely to have been important determinants of Colombia's relative stagnation. Even by Latin American standards, Colombia has been an exceptionally politically unstable country. During the 19th century, there were 13 constitutional amendments or reforms while countries such as Chile or Argentina experienced seven. Moreover, civil conflicts have been particularly violent and costly. For example, citing Aníbal Galindo in Kalmanovitz (2010), the civil conflict known as the Guerra de los Supremos (1841 - 1843), wiped out half of the country's agricultural production.

Finally, an essential point of our case for looking at explanations that are most likely related to technological progress are the special characteristics 
of Colombian geography and in particular its topography. Colombia's landscape has been an important determinant of transportation costs (Safford, 2010). For example, Bertola and Williamson (2006) report that by the middle of the 19th century, Bogotá, one of Latin America's largest capital cities, had the highest transportation costs when measured as the cost of transporting one ton from England to one of these cities. Therefore, our interpretation is that, to the extent that the estimations presented in this paper point in the right direction in terms of prioritizing the main determinants of Colombian growth over the last 200 years in comparison to an industrial leader such as the U.K., the key variables to blame for the longstanding stagnation of relative income per capita are human capital, civil conflict, the institutional framework and topography. 


\section{REFERENCES}

Bertola, L. And J. Williamson (2006), Cabridge Economic History of Latin Amercia, Cambridge University Press, chapter Globalization in Latin America Before 1940.

Cooley, T., ed. (1995), Frontiers of Business Cycles Research, Princeton University Press.

GRECO (2002), El Crecimiento Económico Colombiano en el Siglo XX.

Hansen, G. and E. Prescott (2002), "Malthus to solow," American Economic Review $92,1205-1217$.

Kalmanovitz, S. (2010), Nueva historia económica de Colombia. Santillana.

Lucas, R. (2002), Lectures on economic growth. Harvard University Press.

Maloney, W. (2002), "Missed opportunities: Innovation and resource-based growth in Latin America," Economica 3.

Mariscal, E. and K. Sokoloff (2000), "Political institutions and economic growth in Latin America: Essays in policy, history and political economy," Stanford University, Hoover Institution Press. Chapter "Schoolong, suffrage, and the persistence of inequelity in the Americas, 1800-1945."

Meisel, A. and M. Ramírez, eds. (2010), Economía Colombiana del Siglo XIX. Fondo de Cultura Económica y Banco de la República.

Mokyr, J. (1990), The Lever of Riches. Oxford University Press.

Parente, S. and E. Prescott (2000), Barriers to Riches. The MIT Press.

Ramírez, M. and I. Salazar (2010), Economía Colombiana del Siglo XIX., Fondo de Cultura Económica y Banco de la República, chapter El Surguimiento de la Educacion en Colombia: En qué fallamos.

Safford, F. (2010), Economía Colombiana del Siglo XIX. Fondo de Cultura Económica and Banco de la República. Chapter "El problema de los transportes en Colombia en el siglo XIX."

Urrutia, M. and J. Robinson, eds. (2007), Economía colombiana del siglo XX. Fondo de Cultura Económica and Banco de la República. 


\section{APPENDIX. DATA SOURCES}

- Figure 1: Colombia and U.K. RGDP in 2005 dollars, PPP-adjusted. Colombian RGDP is from Kalmanovitz for the 1805-1905 period and Greco (2002) for the 1905-2005 period. Due to methodological differences in the construction of both series, levels in Greco were backfilled to 1805 using the rates of change of RGDP in Kalmanovitz. U.K. data was taken from Lawrence H. Officer's Measuringworth: http://www.measuringworth.com/ukgdp/. Both series were expressed in 2005 dollars (PPP-adjusted) using the PPP-adjusted exchange rates found in Penn World Table 6.3.

- Figure 2: Data taken from Lawrence H. Officer's Measuringworth: http://www.measuringworth.com/ukgdp/.

- Figure 4: Colombian RGDP is based on Greco (2002). Since this source only contains RGDP from 1905 to 2000, we used the DANE official statistics to complete the series up to 2005. We used the DANE implicit price deflator to express RGDP in 2005 Colombian pesos and then we used Penn World Tables PPPadjusted exchange rate to express everything in 2005 U.S. dollars.

- Figure 5: 19th century population figures are taken from the 1825, 1835, 1843, 1851, 1864, 1870, 1887 and 1898 censuses (Florez, Romero, 2008). From 1905 to 1997 the data is from Greco. From 1998 to 2005 the data is from the DANE censuses and official estimates. All missing values were completed using linear interpolation. Smoothing was done using a Hodrick-Prescott filter with smoothing parameter $\tau=100$.

- Figure 6: Wages for the 19th century were taken from Urrutia (2007). This source included peasants' salaries from Bank of Bogotá and mints and postal service offices in Bogotá and Popayan. A geometric mean was used to aggregate the data. The series for the first half of the 20th century was provided by María del Pilar López's data set; the data for the second half of the 20th century was provided by Urrutia and Ruíz (2010) and consisted in an index built with salaries from industry, public services, construction, commerce, transport and communications, financial services and educational services. Data for the 21st century were taken from DANE. All missing values were completed using linear interpolation. Smoothing was done using a HodrickPrescott filter with smoothing parameter $\tau=100$. 